\title{
The Passage of the Baton to the New Generations
}

\author{
Franco Giovannelli* \\ INAF - Istituto di Astrofisica e Planetologia Spaziali, Via del Fosso del Cavaliere, 100, 00133 \\ Roma, Italy \\ E-mail: Eranco.qiovannellidinaf.it
}

In this short article I would like to capture the attention of all participants and readers on the presence of many young people in our workshop on "The Golden Age of Cataclysmic Variables and Related Objects - V", in order to demonstrate that our community is still lively and that we, elderly researchers, can confidently pass the baton to the younger generations.

The Golden Age of Cataclysmic Variables and Related Objects V (GOLDEN2019)

2-7 September 2019

Palermo, Italy

\footnotetext{
* Speaker.
} 


\section{Introduction}

In this workshop, the presence of women has been particularly pleasant and intentional as well as the presence of many young colleagues, some of them still PhD students or even Master students.

Indeed this is the age of the youth. Young people do not depend on anyone or draw strength from others. The courage of young people is unparalleled. It fears nothing. The courage of youth is boundless, is the strength to never give up (Ikeda, 2001a,b). Even Leonardo da Vinci was used to say "Tristo è lo discepolo che non supera lo maestro suo!", that in English sounds "Grim is the disciple who does not exceed his master!".

\section{The Ceremony}

In order to encourage young people to continue our work, I, as senior researcher and director of this workshop, have the honor and pleasure of passing the baton to new generations of astrophysicists. For this reason I invite Mr Aristarh Chasovnikov and Mr Jaroslav Merc - the youngest participants - to receive a certificate, as shown in Figure 1. This certificate symbolically shows the transition from the first historical workshop of 1984 (Multifrequency Behavior of Galactic Sources) to the present one (The Golden Age of Cataclysmic Variables and Related Objects - V).

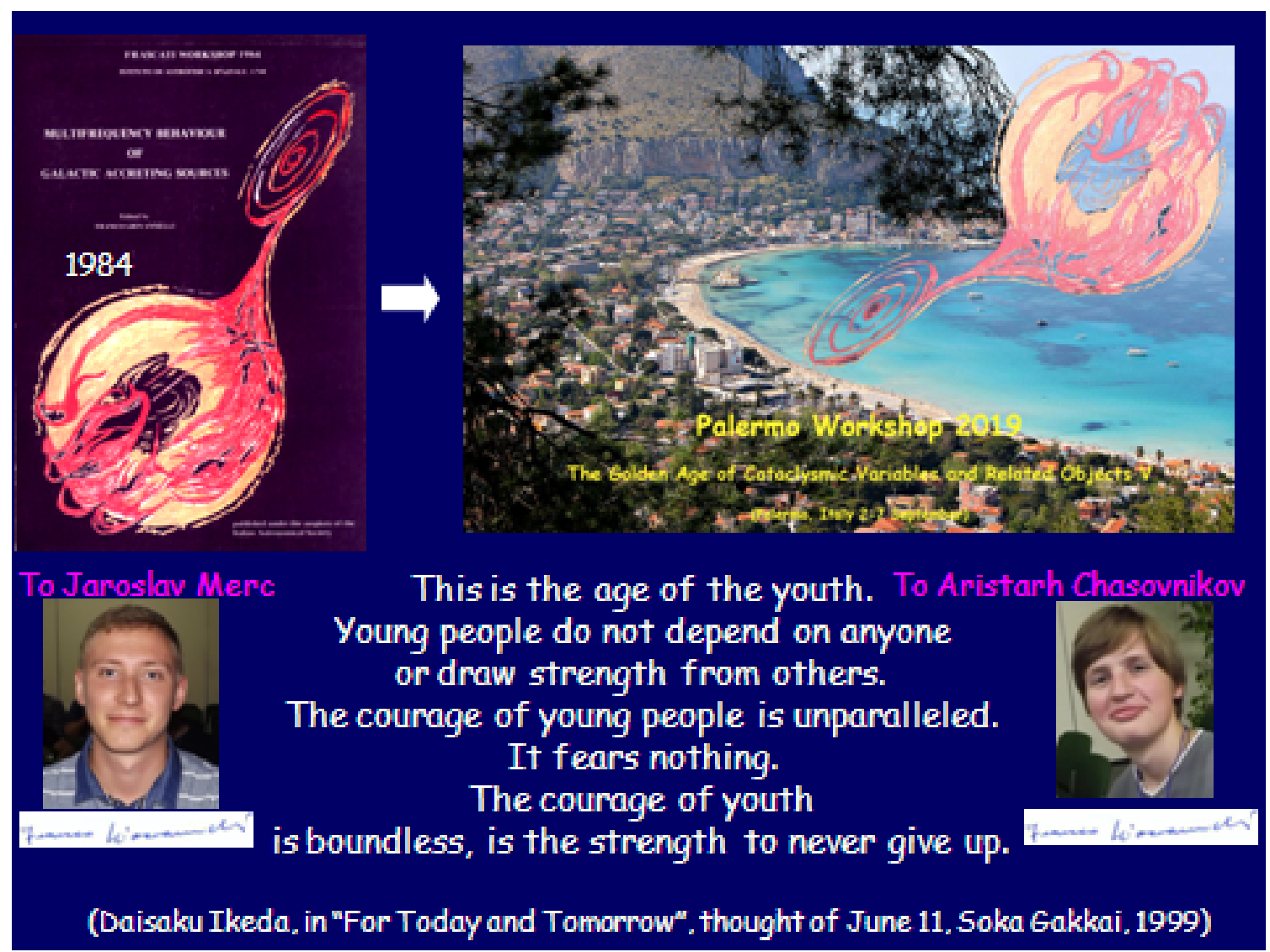

Figure 1: The passage of the baton to new generation of astrophysicists. 
The reader may be taken by curiosity to know my age, as a senior researcher and director of the workshop. I can give the conditions necessary to discover it:

Aristarh's Age $\lesssim 0.35 \times$ Franco's Age $\lesssim$ Jaroslav's Age

Thus, you have all the initial conditions for calculating MY AGE.... and the Physics is saved!

\section{References}

[1] Ikeda, D.: 2001a, For Today and Tomorrow - The thought of 30th May, Edizioni Esperia, Italy.

[2] Ikeda, D.: 2001b, For Today and Tomorrow - The thought of 11th June, Edizioni Esperia, Italy 